\title{
Radiographic Measurement of Cochlear in Sudanese Population using High Resolution Computed Tomography (HRCT)
}

\author{
Lubna Bushara ${ }^{1}$, Mohamed Yousef ${ }^{2}$, Ikhlas Abdelaziz ${ }^{1}$, Mogahid Zidan ${ }^{3 *}$, \\ Dalia Bilal ${ }^{1}$ and Mohammed El Wathig ${ }^{4}$ \\ ${ }^{1}$ Department of Medical Imaging and Radiation Sciences, College of Applied Medical Sciences, University of \\ Jeddah, Jeddah, 21589 Saudi Arabia \\ ${ }^{2}$ Radiologic Sciences Program, Batterjee Medical College, Jeddah, 23819-6700 Saudi Arabia \\ ${ }^{3}$ Department of Radiology, Faculty of Radiology and Nuclear Medicine Sciences, National Ribat University, \\ Khartoum, 11123 Sudan \\ ${ }^{4}$ Siemens Healthcare limited, Jeddah, 21589 Saudi Arabia
}

\begin{abstract}
This study aimed to determine the measurements of the cochlea among healthy subjects and hearing deafness subjects using a High Resolution Computed Tomography (HRCT). A total of 230 temporal bone HRCT cases were retrospectively investigated in the period spanning from 2011 to 2015 . Three 64-slice units were used to examine patients with clinical complaints of hearing loss conditions at three Radiology departments in Khartoum, Sudan. For the control group (A) healthy subjects, the mean width of the right and left cochlear were $5.61 \pm 0.40 \mathrm{~mm}$ and $5.56 \pm 0.58 \mathrm{~mm}$, the height were $3.56 \pm 0.36 \mathrm{~mm}$ and $3.54 \pm 0.36 \mathrm{~mm}$, the basal turn width were $1.87 \pm 0.19 \mathrm{~mm}$ and $1.88 \pm 0.18 \mathrm{~mm}$, the width of the cochlear nerve canal were $2.02 \pm 1.23$ and $1.93 \pm 0.20$, cochlear nerve density was $279.41 \pm 159.02$ and $306.84 \pm 336.9 \mathrm{HU}$ respectively. However, for the experimental group (B), the mean width of the right and left cochlear width were $5.38 \pm 0.46 \mathrm{~mm}$ and $5.34 \pm 0.30 \mathrm{~mm}$, the height were $3.53 \pm 0.25 \mathrm{~mm}$ and $3.49 \pm 0.28 \mathrm{~mm}$, the

ARTICLE INFO

Article history:

Received: 17 September 2020

Accepted: 25 January 2021

Published: 30 April 2021

DOI: https://doi.org/10.47836/pjst.29.2.32

$\overline{\text { E-mail addresses: }}$

arwa6067@gmail.com (Lubna Bushara)

mohnajwan@gmail.com (Mohamed Yousef)

ikhlasabdelaziz888@gmail.com (Ikhlas Abdelaziz)

phd.zidan@gmail.com (Mogahid Zidan)

abhamit@gc.edu.sa (Dalia Bilal)

nafi.m1978@gmail.com (Mohammed El Wathig)

* Corresponding author

basal turn width were $1.76 \pm 0.13 \mathrm{~mm}$, and $1.79 \pm 0.13 \mathrm{~mm}$, the width of the cochlear nerve canal were $1.75 \pm 0.18 \mathrm{~mm}$ and $1.73 \pm 0.18 \mathrm{~mm}$, and cochlear nerve density were $232.84 \pm 316.82$ and $196.58 \pm 230.05$ HU, respectively. The study found there was a significant difference in cochlea's measurement between the two groups with a $p$-value $<0.05$. This study had established baseline measurements for the cochlear for
\end{abstract}


the healthy Sudanese population. Furthermore, it found that HRCT of the temporal bone was the best for investigation of the cochlear and could provide a guide for the clinicians to manage congenital hearing loss.

Keywords: Cochlea, hearing loss, HRCT, measurement

\section{INTRODUCTION}

The hearing or auditory system consists of the inner ear, outer ear, middle ear, and central auditory nervous system. The function of the hearing system is to sense the acoustic environment thus allowing us to detect and perceive sound (Emanuel et al., 2009). The ears are paired organs, one on each side of the head with the sense organ itself, which is technically known as the cochlea, deeply buried within the temporal bones. It is a spiralcavity shaped within the bony labyrinth, in humans making 2.5 turns around its axis. The primary function of the human cochlea is to transform the vibrations into a neural signal.

Innervations of the cochlea involve both efferent and afferent neurons. The efferent nerve supply includes a much smaller population of descending neurons that send signals from the nervous system to the cochlea. The afferent nerve supply is made up of ascending sensory neurons that send signals from the cochlea to the nervous system (Wageih, 2017). The human cochlea is challenging to explore due to its vulnerability and bordering capsule; it is composed of two and threefourth the turns, unusual anatomy with cochlear three turns has been described (Tian et al., 2006).

Congenital inner ear abnormality such as cochlear aplasia, cochlear hypoplasia, and incomplete cochlear partition is a major cause of sensorineural hearing loss (SNHL). Globally, hearing loss causes moderate to severe disability in 124 million people as of 2004 (108 million of whom are in low and middle-income countries) (WHO, 2008). The cochlear malformation is a major cause of hearing loss worldwide. The majority of hearing loss is sensor neural particularly in the elderly and sensor neural hearing loss (SNHL) is primarily a result of damage to the cochlea of the inner ear.

Radiology plays an essential role in the evaluation of congenital sensorineural hearing loss. In children who are candidates for cochlear implantation surgery, it provides vital preoperative information about the inner ear, the vestibulocochlear nerve, and the brain. Computed Tomography (CT) and Magnetic Resonance Imaging (MRI) provides excellent delineation of the intricate anatomy of the inner ear: CT depicts the minute details of osseous structures, and MRI allows visualization of the fluid-filled spaces and the vestibulocochlear nerve (Joshi et al., 2012).

A retrospective study by Fernando et al. (2011) described the cochlear anatomy among Filipino through high resolution computed tomography (HRCT) imaging. Other retrospective study by Teissier et al. (2010) established normative measurements of the inner ear using temporal bone CT scan to aid in the diagnosis of inner ear malformations as 
prospective measurements of the structures of the inner ear. Teissier et al. (2010) established CT measurements of the normal cochlea in children and determined radiological criteria correlated with SNHL. The study was a retrospective study of temporal bone CT performed in 159 children, age range from 3 days to 16 years between February 1999 and July 2004. A control group $(n=88)$ comprised of children without SNHL; the SNHL group comprised of 71 children. The width of the second turn of the cochlea $(\mathrm{CW})$, the cochlear height $(\mathrm{CH})$, and the width of the bony canal for the cochlear nerve (WCN) were measured on a reference plane containing the modiolus, the posterior semicircular canal, the footplate, and the stapes arch (Teissier et al., 2010).

The standard treatment for patients who experience sensorineural hearing loss is cochlear implants (CIs). All recent studies have shown that hearing outcome correlated with intra-cochlear anatomy and electrode placement. Furthermore, there are no local studies has been reported for the establishment of a normal measurement for Sudanese cochlea comparing with cochlear measurements for deaf patients. So the significance of this study provides extra information about the cochlear dimensions for Sudanese to use, especially in cochlear implantation.

The purpose of this retrospective study was to characterise the anatomy of the cochlea on Sudanese through an HRCT scan to set reference values of the normal related to abnormal measurements.

\section{MATERIALS AND METHODS}

This cross-sectional retrospective study for normal measurements of the human cochlea, was performed in Al-Amal Hospital, Military Hospital and Royal Care International Hospital, from January 2011 until January 2015.

\section{Study Population}

A total of 230 HRCT of the temporal bone for Sudanese subjects were included, 460 right and left ears, in both genders. They were divided them into two groups, group A for normal hearing subjects, and group B for bilateral congenital hearing losssubjects.

\section{Group A: Healthy Subjects Control Group}

Two hundreds (200) normal hearing were examined by audiometric tests, 137 males and 63 females, who ranged between 1-84 years old.

\section{Inclusion Criteria for Group A}

The Sudanese male and female, aged between 1-90 year. Normal hearing grade exclusion criteria: all participants who had cochlear abnormality or sensorineural hearing loss an etiological investigation after or before cochlear implants were excluded. 


\section{Group B: Experimental Group}

This group consisted of 30 volunteers with bilateral congenital deafness confirmed by audiometric tests (12 males and 18 females), in different ages between 10 to 30 years.

\section{Data Collection}

The data were collected by measurements of different variables which include, cochlea width $(\mathrm{CW})$, cochlea height $(\mathrm{CH})$, a width of cochlear nerve canal $(\mathrm{CNCW})$, Basal turn width (BTW), density of the cochlear nerve, and cranium transverse diameter recorded from a reconstruction of brains in HRCT scanning. Ages and gender were recorded. A clinical data collection sheet was designed, and it contained all the variables of the study.

\section{Data Analysis}

Differences in cochlear measurements between Group A and B were analyzed using the ANOVA test. These analyses were performed using SPSS statistical software (SPSS for Windows, version 16; SPSS Inc, USA, Chicago, IL,). A p-value $<0.05$ was considered statistically significant.

\section{Instrumentation}

Both 64 slice spiral CT units (Toshiba (Aquilon) and Siemens (Somatom plus) Medical Systems) were used to examine patients for HRCT scans temporal bones.

\section{Data Acquisition and Measurement Protocol}

Volumetric acquisition parameters were $\mathrm{kV}$ settings $120 \mathrm{kV}, 350 \mathrm{mAs}, 0.5 \mathrm{~mm}$ slice thickness, $70 \mathrm{~mm}$ field of view, Effective pitch of 0.85 , the effective thickness of about $0.75 \mathrm{~mm}$, HRCT images were reconstructed with a thickness of sequential $2 \mathrm{~mm}$, brain window levels of 35-45, brain window widths of 110-160, bone window levels of 450, and bone window widths of 1600 .

\section{Measurements}

The protocol used in this study was designed to visualizing details of bone outline for accurate measurements. The dimensions of cochlear were calculated from the axial sections: the width of the bony canal for the cochlear nerve was measured at the entry of the cochlea (WCN), both height $(\mathrm{CH})$ and width of the cochlea $(\mathrm{CW})$ was defined as the second turn at the reference slice level also the second turn of the cochlea was measure parallel to the latter X (Figure 1). Thecochlear canal was measured tangentially to two inferior extremities of the X-shaped modiolus (Figure 2). The length between orthogonal projection passing through the canal and the cochlear tip was defined as the cochlear height. 


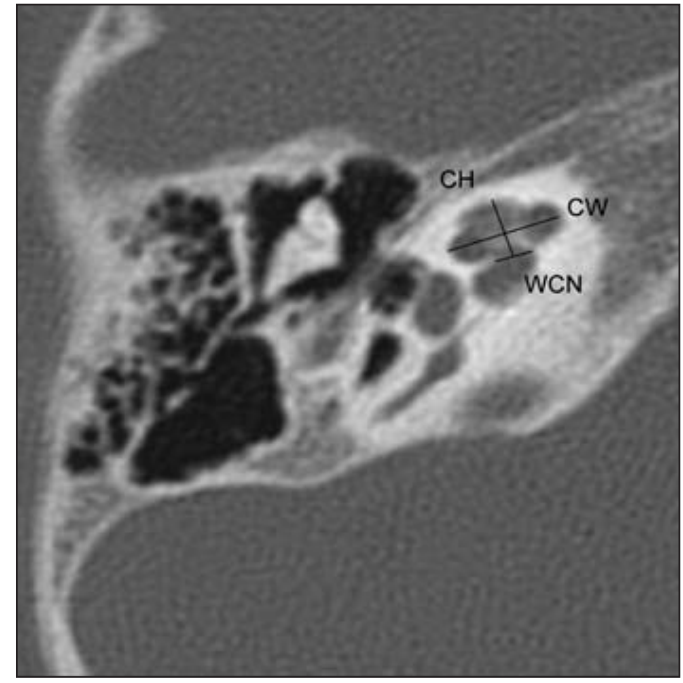

Figure 1. Bone window CT axial view of the right cochlea demonstrating the method of the measurement at the reference plane (X-shape)

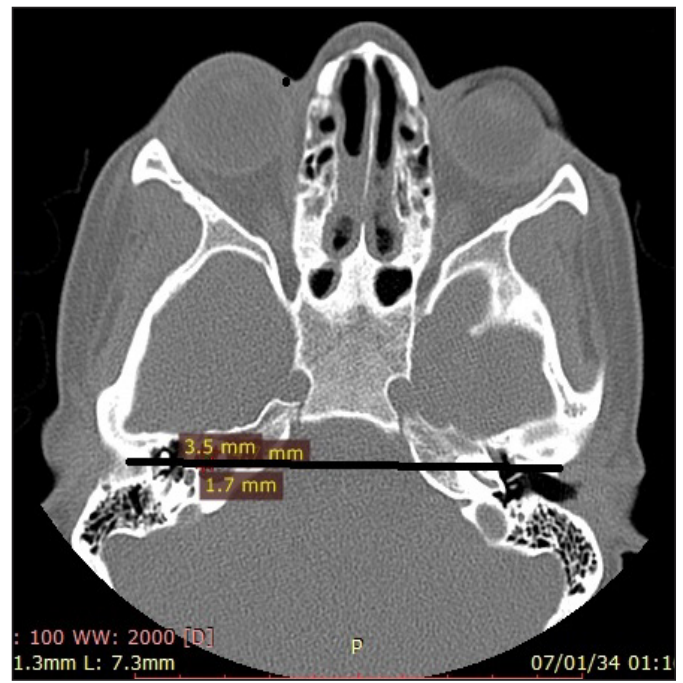

Figure 2. Bone window CTaxial view temporal bone demonstrating transverse cranial width (TCW) measurement from the bony borders right to the light side

The basal turn width (BTW) measured from the sagittal section of the same slice obtained by MPR at the same slice level, bone window with filtering adjacent was used to provide an optimal image contrast to define the boundaries more precisely.

\section{RESULTS}

Two hundred and thirty $(\mathrm{n}=230)$ study participants between 1 to 84 years of age met inclusion criteria for this study; 63 females (42.26 \pm 17.85 years of age) and 137 males ( $37.26 \pm 20.48$ years of age). Table 1 shows measurements of cochlea according to gender. A statistical difference was not noted between females and males. Therefore, it was of interest to determine whether gender of the patient could not affect cochlea measurements.

Table 2 and 3 show measurements of cochlea in both sides for group both groups. However, there was a significant difference in CT numbers between the two groups where it was found that the CT Number in a normal people group was higher than in people who suffered from hearing loss .

Table 2 and 3 show measurements of cochlea in both sides for group both groups. However, there was a significant difference in CT numbers between the two groups where it was found that the CT Number in a normal people group was higher than in people who suffered from hearing loss .

Table 4 demonstrates that there are differences concerning the size of the cochlear, as it appears that both cochlear in people who have hearing loss seem smaller when compared to normal people. Thus the size of the cochlea in normal hearing subjects was significantly different from subjects with hearing loss. 
Table 1

Measurements of the Cochlea in both gender

\begin{tabular}{lccc}
\hline Variables & Gender & Mean & Std. Deviation \\
\hline Age & Male & 37.26 & 20.48 \\
LT cochlea width & Female & 42.24 & 17.85 \\
& Male & 5.58 & 0.66 \\
LT cochlea height & Female & 5.52 & 0.38 \\
& Male & 3.58 & 0.37 \\
LT cochlea nerve canal width & Female & 3.51 & 0.35 \\
& Male & 2.08 & 1.47 \\
LT basal turn width & Female & 1.89 & 0.21 \\
& Male & 1.87 & 0.19 \\
LT means of CT number of the cochlea nerve & Female & 1.89 & 0.17 \\
& Male & 277.78 & 153.11 \\
RT cochlea width & Female & 282.95 & 172.41 \\
& Male & 5.64 & 0.41 \\
RT cochlea height & Female & 5.53 & 0.39 \\
& Male & 3.57 & 0.36 \\
RT cochlea nerve canal width & Female & 3.47 & 0.34 \\
RT basal turn width & Male & 1.95 & 0.21 \\
RT mean of CT number of the cochlea nerve & Female & 1.89 & 0.19 \\
Cranium/transverse diameter & Male & 1.88 & 0.19 \\
& Female & 1.87 & 0.16 \\
& Male & $322 . .26$ & 394.61 \\
& Female & 273.30 & 145.83 \\
& & 121.11 & 9.15 \\
& 122.03 & 4.25 \\
\hline
\end{tabular}

Table 2

Measurements of left and right cochlea in (Group A)

\begin{tabular}{lcc}
\hline Variables & Left cochlea & Right cochlea \\
\hline Cochlea width/mm & $5.59 \pm .0 .58$ & $5.60 \pm 0.40$ \\
Cochlea height $/ \mathrm{mm}$ & $3.56 \pm 1.23$ & $3.54 \pm 0.36$ \\
Cochlea nerve canal width/mm & $2.02 \pm 1.20$ & $1.93 \pm 0.20$ \\
Basal turn width/mm & $1.87 \pm 0.18$ & $1.88 \pm 0.18$ \\
CT number of Cochlea nerve/HU & $279.41 \pm 159.02$ & $306.84 \pm 336.99$ \\
\hline
\end{tabular}

Table 3

Measurements of left and right cochlea in (Group B)

\begin{tabular}{lcc}
\hline Variables & Right cochlea & Left cochlea \\
\hline Cochlea width/mm & $5.38 \pm 0.46$ & $5.34 \pm .0 .30$ \\
Cochlea height $/ \mathrm{mm}$ & $3.49 \pm 0.28$ & $3.53 \pm 0.25$ \\
Cochlea nerve canal width/mm & $1.73 \pm 0.18$ & $1.75 \pm 0.18$ \\
Basal turn width/mm & $1.79 \pm 0.13$ & $1.76 \pm 0.13$ \\
CT number of Cochlea nerve/HU & $196.58 \pm 230.05$ & $232.84 \pm 316.82$ \\
\hline
\end{tabular}


Table 4

Measurements of Cochlea's in (Group B) and (Group A)

\begin{tabular}{lccc}
\hline Variables & Group & Variables Mean & Std. Deviation \\
\hline \multirow{2}{*}{ LT Cochlea width } & B & 5.34 & 0.30 \\
& A & 5.59 & 0.58 \\
LT Cochlea height & B & 3.53 & 0.25 \\
& A & 3.56 & 1.23 \\
LT Cochlea nerve canal width & B & 1.75 & 0.18 \\
& A & 2.02 & 1.20 \\
LT Basal turn width & B & 1.76 & 0.13 \\
& A & 1.87 & 0.18 \\
RT Cochlea width & B & 5.38 & 0.46 \\
RT Cochlea height & A & 5.60 & 0.40 \\
RT Cochlea nerve canal width & B & 3.49 & 0.28 \\
RT Basal turn width & A & 3.54 & 0.36 \\
& B & 1.73 & 0.18 \\
& A & 1.93 & 0.20 \\
& B & 1.79 & 0.13 \\
\end{tabular}

\section{DISCUSSION}

The familiarity of the anatomical measurement of the cochlea is insufficient compared to other sensory systems due to difficulties in examining inner ear structures. The measurement of cochlea dimensions using High resolutions computed tomography was implemented to evaluate the length of the cochlea using a CT scan. The length was described to be about $33.01 \pm 2.31 \mathrm{~mm}$ (Nemzek et al., 1996). In this study cochlear dimension was measured for both normal subjects and subjects with congenital deafness in different ages, and for both genders using high resolution computed tomography.

The variables in group A demonstrated that the width of the right and left cochlear were found to be $5.60 \pm 0.40 \mathrm{~mm}$ and $5.59 \pm 0.58 \mathrm{~mm}$, respectively, and the height of right and left cochlear were found to be $3.54 \pm 0.36 \mathrm{~mm}$ and $3.56 \pm 1.23 \mathrm{~mm}$, the width of cochlear basal turn were a measure to be $1.87 \pm 0.19 \mathrm{~mm}$ for the left cochlear and $1.88 \pm 0.18 \mathrm{~mm}$ for the right cochlear. Also the widths of right and left Cochlear nerve canals were $2.02 \pm 1.2$ $\mathrm{mm}, 1.93 \pm 0.2 \mathrm{~mm}$, respectively.

In addition, CT attenuation for the cochlear nerve was measured, and it was found to be $279.41 \pm 159.02 \mathrm{HU}$ for the left cochlear nerve and $306.84 \pm 336.9 \mathrm{HU}$ for the right cochlear. These were the standard measures of normal Sudanese cochlea found by this study. In group B, the measurement was performed for Sudanese patients who have congenital hearing loss. For this group, the width of the right and left cochlear was found to be $5.38 \pm 0.46 \mathrm{~mm}$ and $5.34 \pm 0.30 \mathrm{~mm}$, respectively. The height of right and left cochlear 
was found to be $3.49 \pm 0.28 \mathrm{~mm}$ and $3.53 \pm 0.25 \mathrm{~mm}$, respectively. The width of the cochlear basal turn was a measure to be $1.76 \pm 0.13 \mathrm{~mm}$ for the left cochlear and $1.79 \pm 0.13 \mathrm{~mm}$ for the right cochlear. Also the width of the right and left cochlear nerve canal was $1.73 \pm 0.18$ $\mathrm{mm}$ and $1.75 \pm 0.18 \mathrm{~mm}$, respectively. $\mathrm{CT}$ attenuation for the cochlear nerve in group B was $232.84 \pm 316.82 \mathrm{HU}$ for the left cochlear nerve and $196.58 \pm 230.05 \mathrm{HU}$ for the right cochlear nerve.

This study confirmed that there was no anatomical differences in the cochlear measurements on the left and right side in both groups (Table $1 \& 2$ ).

Furthermore, our results found that there was no significantdifferences between the measurement of the cochlea in both gender (Table 1). Mclay et al. (2002) explained that there was a possible variation between cochlear width, height with age. The height and width of cochlear in our study did not change with age; this was in agreement with the study done by Mori and Chang (2012) who concluded that there was no change in cochlear height from childhood to adulthood.

The importance of measuring cochlear height in this study is because all physicians believe in the use of cochlear height in the diagnosis of Sensorial hearing loss for the patients diagnosed with hypoplasia or hyperplasia. Concerning the cochlear height, we found a cochlear height difference in a normal population (Group A) and patients suffering congenital hearing loss (Group B). Using axial CT scans $3.54 \pm 0.36 \mathrm{~mm}$ was found for the right cochlea and $3.56 \pm 1.23 \mathrm{~mm}$ for the left cochlea in group A and $3.49 \pm 0.28 \mathrm{~mm}$ for the right cochlea and $3.53 \pm 0.25 \mathrm{~mm}$ for the left cochlea in group $B$. In the studies conducted by Purcell et al. (2006), they found the cochlear height for a normal population on coronal CT scans of the temporal bone was ranged from $4.4 \mathrm{~mm}$ to $6.2 \mathrm{~mm}$, while cochlear height in control patient was ranged from $4.1 \mathrm{~mm}$ to $2.7 \mathrm{~mm}, \mathrm{p}>0.001$ ). Our results on cochlear height in both group were in agreement with the results of Purcell et al. (2006).

In the current study, we noticed that there was a significant relation $(\mathrm{p}<.05)$ between age and cochlear nerve attenuation, a width of the right cochlear nerve, and a transverse cranial dimension. Our results differ from the results found by Teissier et al. (2010). This difference might be due to the fact that our study was preformed in the adult population, and Teissier et al. (2010) focused on the pediatric group.

Furthermore, Our results demonstrate that the size of cochlea increase with age and this is compatible with the study conducted by Marshall (1981), where they found that the cochlear and cochlear nerve size increased with increasing the age. Moreover, when comparing the size of the cochlea in both normal hearing subjects and subjects suffering from hearing loss, we reported that the size of the cochlea in normal hearing subjects was significantly different from subjects with hearing loss (Table 4).

Moreover, this occured both when the cochlea was considered abnormal at visual inspection and when no major malformation was diagnosed. 
Our results consigned to what was acknowledged by Teissier et al. (2010). Moreover, our results showed that the normal cochlear in both groups showed no noticeable difference radiographically. However, an embryological or genetic defect, from a clinical point of view, may influence the size of the ears, and this caused a congenital hearing loss. In the current study, the size of the cochleas in people who have hearing loss it appears seemed smaller when compared to normal people (Table 4). Our resuts which is similar to the study conducted by Fatterpekar et al. (2000) where they found the width and height of the cochlear neural canal in people with hearing loss was significantly smaller when compared to a group of normal people.

Furthermore, the results obtained in this study showed that there was a significant difference in CT numbers between the two groups where it was foundthat the CT Number in a normal people group was higher than in people who suffer from hearing loss (Table 2 \& 3). To our knowledge, the auditory nerve CT numbers in our study decreased with increasing age. Our findings on Age-Related differences in CT numbers were compatible with the results of Stafford et al. (1988), where they found the CT density numbers decreased linearly with increasing age.

The heterogeneity of the population limits this study because of the randomized selection process. Other limitations of this study were: i) There was a relatively small cohort sample; ii) Lack of previous research studies on the topic iii) A high standard deviation was recoreded due wider range of age variation. However, to the best of our knowledge, numerous authors have attempted to characterize normative measurements of inner ear structures when evaluating SNHL by CT.

However, this study reflects the necessitate of coming across the normative values to differentiate between the normal from pathological conditions, additionally necessary for accurate interpretation of the inner ears radiographs, which thus signifies the importance of this study.

\section{CONCLUSION}

In conclusion, this study had established baseline measurements for the cochlear for the healthy Sudanese population. These baseline measurements should be included in the checklist when interpreting a CT scan in cases of SNHL. Furthermore, radiographically there is no significant difference in cochlear radiographic appearance regarding ages and gender. Besides, we found that HRCT of the temporal bone is the best for investigation of the cochlear and can provide a guide for the clinicians to manage congenital hearing loss.

\section{ACKNOWLEDGMENTS}

We thank all the hospitals from which we collected the data and for their patience during the preparation of this article. 


\section{REFERENCES}

Emanuel, D., Sumalai, M., \& Letowski, T. (2009). Auditory function: Physiology and function of the hearing system. Helmet-Mounted Displays: Sensory, Perceptual, and Cognitive Issues, Edition, 1, 307-334.

Fatterpekar, G. M., Mukherji, S. K., Alley, J., Lin, Y., \& Castillo, M. (2000). Hypoplasia of the bony canal for the cochlear nerve in patients with congenital sensorineural hearing loss: Initial observations. Radiology Radiology, 215(1), 243-246. https://doi.org/10.1148/radiology.215.1.r00ap36243

Fernando, A., Jesus, B., Opulencia, A., Maglalang, G., \& Chua, A. (2011). An anatomical study of the cochlea among filipinos using high-resolution computed tomography scans. Philippine Journal of Otolaryngology Head and Neck Surgery, 26(1), 6-9. https://doi.org/10.32412/pjohns.v26i1.591

Joshi, V. M., Navlekar, S. K., Kishore, G. R., Reddy, K. J., \& Kumar, E. V. (2012). CT and MR imaging of the inner ear and brain in children with congenital sensorineural hearing loss. Radiographics, 32(3), 683-698. https://doi.org/10.1148/rg.323115073

Marshall, L. (1981). Auditory processing in aging listeners. The Journal of Speech and Hearing Disorders, 46(3), 226-240. https://doi.org/10.1044/jshd.4603.226

McClay, J. E., Tandy, R., Grundfast, K., Choi, S., Vezina, G., Zalzal, G., \& Willner, A. (2002). Major and minor temporal bone abnormalities in children with and without congenital sensorineural hearing loss. Archives of Otolaryngology-Head \& Neck Surgery, 128(6), 664-671. https://doi.org/10.1001/archotol.128.6.664

Mori, M. C., \& Chang, K. W. (2012). CT analysis demonstrates that cochlear height does not change with age. American Journal of Neuroradiology, 33(1), 119-123. https://doi.org/10.3174/ajnr.A2713

Nemzek, W. R., Brodie, H. A., Chong, B. W., Babcook, C. J., Hecht, S. T., Salamat, S., Ellis, W. G., \& Seibert, J. A. (1996). Imaging Findings of the Developing Temporal Bone in Fetal Specimens. American Journal of Neuroradiology, 17(8), 1467-1477.

Purcell, D. D., Fischbein, N. J., Patel, A., Johnson, J., \& Lalwani, A. K. (2006). Two Temporal Bone Computed Tomography Measurements Increase Recognition of Malformations and Predict Sensorineural Hearing Loss. The Laryngoscope, 116(8), 1439-1446. https://doi.org/10.1097/01.mlg.0000229826.96593.13

Stafford, J. L., Albert, M. S., Naeser, M. A., Sandor, T., \& Garvey, A. J. (1988). Age-related differences in computed tomographic scan measurements. Archives of Neurology, 45(4), 409-415. https://doi.org/10.1001/ archneur.1988.00520280055016

Teissier, N., Van Den Abbeele, T., Sebag, G., \& Elmaleh-Berges, M. (2010). Computed tomography measurements of the normal and the pathologic cochlea in children. Pediatric Radiology, 40(3), 275-283. https://doi.org/10.1007/s00247-009-1423-2

Tian, Q., Linthicum, F. H., \& Fayad, J. N. (2006). Human cochleae with three turns: An unreported malformation. The Laryngoscope, 116(5), 800-803. https://doi.org/10.1097/01.mlg.0000209097.95444.59

Wageih, G. (2017). Ear Anatomy. Global Journal of Otolaryngology, 4(1), Article 555630. https://doi. org/10.19080/GJO.2017.04.555630

WHO. (2008). The global burden of disease 2004. World Health Organization. 